\title{
Meta-analysis of phosphorus loss from no-till soils
}

AUTHORS: S. Daryanto, L. Wang*, P.A. Jacinthe

Department of Earth Sciences, Indiana University Purdue University, Indianapolis, IN 46202

NUMBER OF PAGES (including abstract and references): 29

NUMBER OF TABLES: 1

NUMBER OF FIGURES: 3

\section{CORRESPONDING AUTHOR:}

*Dr. Lixin Wang

Department of Earth Sciences, Indiana University Purdue University Indianapolis (IUPUI)

723 W. Michigan Street, SL 118M, Indianapolis, IN 46202

Phone: (317) 274-7764; Fax: (317) -274-7966; E-mail: lxwang.@iupui.edu
Abbreviation list:
NT = no-tillage
$\mathrm{CT}=$ conventional tillage
$\mathrm{P}=$ phosphorus 


\title{
CORE IDEAS
}

1. No-till (NT) was effective in reducing particulate P loss, but not dissolved P loss

2. NT co-varied with several physical and management variables in affecting P loss

3. NT needs to be combined with other land management strategies to reduce dissolved P loss

\begin{abstract}
Agriculture is a significant contributor to phosphorus (P) enrichment in aquatic ecosystems. Notill (NT) farming has been proposed as an alternative approach to conventional tillage (CT) in reducing soil $\mathrm{P}$ export, but published data have shown contrasting impacts, likely due to the interacting effects of different physical (climate region, rainfall variability, transport pathways, slope gradient) and management variables (NT duration, crop species). We conducted a metaanalysis to understand the extent to which each of these variables controls the concentration and load of different $\mathrm{P}$ fractions (dissolved $\mathrm{P}$, particulate $\mathrm{P}$ ) in agricultural runoff and leaching. In comparison to CT, particulate P loss was significantly lower with NT adoption (45\% and 55\% reduction in concentration and load, respectively), but an increase in dissolved P loss was observed. The extent of the reduction or increase, however, varied with different physical and management variables. In comparison to CT for example, NT was not effective in reducing particulate P concentration during wet years, and particulate P load on steep slopes (4-9\%). Total P concentration was also similar with CT at sites under prolonged NT duration ( 10 years) and at NT fields planted with soybean. Our results underscore the need to consider the co-varying physical and management factors when assessing the potential of NT farming in controlling P
\end{abstract}


loss in the environment. The limited impact of NT on dissolved P loss remains a serious impediment toward harnessing the water quality benefits of this management practice.

Keywords: leaching, runoff, crop, eutrophication, tillage management

\section{Introduction}

Phosphorus (P) has long been recognized as a key element in the eutrophication process, including the proliferation of toxic algae blooms and the formation of "dead zones" in different aquatic ecosystems (Conley et al., 2009). Global P budget has indicated a 75\% increase (relative to pre-industrial level) in net $\mathrm{P}$ storage in terrestrial and aquatic ecosystems, largely due to $\mathrm{P}$ fertilization of agricultural soils (Bennett et al., 2001; Zhou et al., 2017). Excessive fertilization of croplands leads to increased soil test P (STP) values over time (Carefoot and Whalen, 2003; Dodd and Mallarino, 2005). The number of agricultural soils with high STP values has doubled between the 1960's and the 2000's (Dodd and Mallarino, 2005). Once delivered to surface water bodies, $\mathrm{P}$ is efficiently retained by a combination of biological assimilation and sediment deposition processes, ultimately resulting in sediment P enrichment (Correll, 1998). Examination of the full ecological impact of $\mathrm{P}$, however, has been challenging in part due to the wide variety of forms in which P exists in natural waters (e.g., dissolved and particulate phases, inorganic and organic forms) (Jarvie et al., 2002). Consequently, many P-reduction programs have failed to achieve their broader water quality protection goals (e.g., in estuaries and coastal ecosystems), although improvement has been reported in many freshwater ecosystems (e.g., lakes) (Conley et al., 2009).

With the recognition that excess $\mathrm{P}$ in aquatic systems primarily originates from agricultural fields, different land management practices have been proposed as options to mitigate P export. 
Proposed techniques include retention of crop residues on the soil surface and the use of cover crops during the fallow period (Dumanski et al., 2006). These practices are collectively known as “conservation agriculture”, with no-till (NT or zero tillage) being the foundation of this farming philosophy (Dumanski et al., 2006). NT is an agricultural practice in which seeds are planted directly in the residue left by the previous crop. With the exception of small slits for deposition of seeds, the soil is largely undisturbed under NT farming (Horowitz et al., 2010). The practice thus creates minimum soil disturbance, reduces erosion and increases soil cover compared to conventional tillage (CT) management.

Variable effects of NT on soil P loss have been reported, likely due to the various physical (e.g., transport pathway, rainfall variability) and management factors (e.g., crop species, tillage duration) affecting P transport in agricultural landscapes (Amon-Armah et al., 2013). Surface transport primarily consists of runoff, which involves interactions of water with nutrients in the surface soil layers. Sub-surface transport is dominated by leaching, including preferential flow through soil macropores and piston-type flow through micropores of the soil matrix (Kleinman et al., 2009). Changes in hydrological conditions (e.g., more frequent drought or flood) could further influence the amount of P carried into the waterways as they affect the amount of water leaving an agricultural system (Randall and Mulla, 2001). The variability of the impact of NT on $\mathrm{P}$ export could also be associated with soil drainage characteristics as increase in total runoff $\mathrm{P}$ loss following manure application can be 3-7 times greater in clay-rich compared to well-drained soils under NT (Kleinman et al., 2009). The impact of NT could also vary depending on the duration of NT management; while beneficial effects can be observed in the short-term, it is not inconceivable that soil P mobility can be differently affected under long-term NT due to greater 
abundance of macropores and soil compaction which may enhance leaching and runoff, respectively (Holland, 2004).

Partially due to the factors listed above, the literature reviewed herein has shown considerable variability on the effects of NT on P loss from agricultural fields. In this study, we conducted a comprehensive comparison between NT and CT management practices with regard to $\mathrm{P}$ loss (both concentration and load for different $\mathrm{P}$ fractions) by conducting a meta-analysis to examine how NT practice co-varies with physical (i.e., transport pathway, rainfall variability) and management factors (i.e., crop species, NT duration) to affect P mobility. Meta-analysis was assumed to be an effective approach to disentangle the co-varying factors controlling the export of P from agricultural fields. In general, NT management contributes to the improvement of various aspects of the crop-soil relationship including soil temperature, organic matter content, water retention and infiltration (Triplett and Dick, 2008). No-till practices can significantly reduce soil erosion and runoff volume, but at the same time can increase water infiltration and leaching (Holland, 2004). While vegetative growth and fertilizer-use efficiency are generally better when crops are grown under NT management (Francis and Knight, 1993), these results may vary with climatic conditions (Ogle et al., 2012). Based on the generally positive impacts of NT on soil properties, we expected that: (i) NT practice would reduce P export by controlling both the volume and P concentration in waters leaving agricultural fields, although (ii) the extent of NT impact on water quality could be different depending on whether P concentration or P load is considered in the assessment. We anticipated that high concentration of $\mathrm{P}$ in drainage waters would not always translate into high load of $\mathrm{P}$ and vice versa since the amount of $\mathrm{P}$ leaving an agricultural system is the product of water volume and P concentration (Randall and Mulla, 2001). 


\section{Methods}

Peer-reviewed journal articles published in English from 1985 to 2016, and referenced in the Web of Science and Scopus systems, were collected to build the database used for this metaanalysis. The literature search was conducted using the following sets of topic keywords: (i) direct drilling or direct sowing or tillage or plow or plough, (ii) phosphorus or water quality, and (iii) soybean or corn or wheat. We selected those three crops based on FAO Crop Production Statistics (FAO, 2012) showing that these crops are likely to be cultivated using both NT and CT practices. In the context of this analysis, we defined conventional tillage (CT) as a land management practice involving various types of tillage implements (e.g., moldboard, rotary, chisel and disking), and NT as zero tillage. A total of 1772 and 914 articles were identified from Web of Science and Scopus, respectively. Out of this total, only articles that reported the concentration and/or load of P in paired NT vs CT practices, including lysimeter studies under field conditions, were included in the database. Since we focused on understanding the effect of NT (including its long-term impact) on P loss, we did not include articles stemming from studies involving “one-time tillage” experiments at sites previously under long-term NT since such results could introduce artifacts in the dataset. The articles consulted for this meta-analysis are listed in Table 1, with full reference of each article provided in Supplemental Material S1.

The data were recorded separately for concentration and load of soluble P, particulate $\mathrm{P}$ and total P (the sum of dissolved and particulate P). These fractions were selected to simplify the presentation of the numerous chemical P forms that can be present in natural waters (Jarvie et al., 2002). The magnitude of $P$ loss was then examined in relation to several categorical variables (i.e., physical and management factors), except when constrained by data availability. Physical 
categorical variables included: (i) rainfall variability (i.e., wet, normal, and dry years), (ii) transport pathway (i.e., surface runoff and leaching), (iii) slope gradient (0-3\% and 4-9\%), and (iv) climate region (i.e., dryland and non-dryland). Management categorical variables included: (i) crop species (i.e., wheat, soybean, or corn), and (ii) tillage duration (i.e., short, medium, and long). We considered short-term tillage if the practice was adopted for $<5$ years, medium-term if it was in place for 6-10 years, and long-term if the practice was applied for $>10$ years (Al-Kaisi and Yin, 2004). The duration of the tillage practice was calculated as the time length between the start of NT treatment and the time of observation. For the purpose of this meta-analysis, we established discrete levels for each variable, and coded each observation accordingly. Slope was differentiated according to the classification used by Agriculture and Agri-Food Canada (2013), and climate according to aridity indices (Daryanto et al., 2016, 2017). While this categorization allowed us to tease out each of the co-varying factors that could affect P loss, it should be noted that this categorization has also led to: (i) non-representation of some categories in the analysis due to data availability constraints, or (ii) some categorical variables were investigated in only a few studies, and this could limit the explanatory power of these variables.

Due to variations in land cultivation practices, other criteria were imposed when calculating the effect of NT for each category. For example, in calculating the effect of crop species, we were unable to quantify the effect of crop rotation because rotation necessarily involves different crop species. The effect of rotation also spans over a time period longer than a growing season. Using the same line of reasoning, data points that averaged $\mathrm{P}$ concentration or load across multiple years were excluded from the determination of the effect of crop species since these data points may include several crop species. Therefore, in order to account for the effect of each crop species, only studies that investigated one crop in a growing season (instead of 
intercropping or polyculture) were included in assessing the co-varying effect of crop species. Similar criteria were also imposed when assessing the effect of rainfall variability. Since we were interested in differentiating the impact of tillage practices during dry and wet years, we recorded the amount of rainfall for each year (or growing season) of observation reported in the study when evaluating the effect of rainfall variability. These precipitation amounts were compared to long-term average for the region, and the sampling period was defined as "dry year" if the amount of rainfall was $10 \%$ below average (Hisdal et al., 2000). A similar deviation (surplus) was applied to define "wet year”. This deviation was used because a large deviation would otherwise indicate an extreme weather condition, which is usually much rarer than smaller deviation during the time-scale of most agricultural experiments. Therefore, we did not include studies that only reported the average amount of nutrient loss across multiple years when evaluating the effect of rainfall variability since the average values cannot reflect possible changes in nutrient loss with annual variations in rainfall amounts. We also did not include studies that involved rainfall simulation or irrigation when evaluating the effect of rainfall variability, although these data points were included in calculating the effects of other co-varying variables (e.g., transport pathway).

We applied a rigorous procedure to ensure the independence of each data entry, avoiding over-representation of any particular study and reducing publication bias (Lu et al., 2016). For example, if leaching measurements were made at several depths during a study, we averaged the response of each depth and only a single data entry was used in the meta-analysis. Similarly, if a study reported different sampling intervals (e.g., monthly or weekly, phenological phases), the response was arithmetically averaged (as not all studies provided the amount of water volume), and only one sampling time (i.e., the annual or growing season) was used in the meta-analysis, 
resulting in a single data point for that corresponding year or growing season. However, if a study examined the effect of tillage in combination with other agronomic factors (e.g., fertilizer type, tillage method), the data were treated as separate contributions (Lu et al., 2016). Similarly, if a study was conducted in different years or locations, the data were treated separately since a given field could have experienced different rainfall conditions over the years or been planted with different crops during a rotation. We, however, did not differentiate between the timing of the observation (e.g., annual or growing season) when evaluating the effect of NT as the impact of NT on water quality is expected not to be limited to just a few sampling periods.

There were 126, 60, and 45 data points from 20, 13 and 12 studies for soluble P, particulate P, and total P concentrations, respectively. For P loads, there were 83, 52 and 39 data points from 20, 10 and 10 studies for soluble $P$, particulate $P$ and total $P$, respectively. The database included only one study conducted at a site equipped with artificial drainage, so the potential bias that could arise from tile drainage should be minimum (Supplemental Table S1).

To quantify the difference in P export due to NT, meta-analysis was used to construct the confidence intervals for each categorical variable. Since standard deviation was reported in only four (out of 27) articles, we performed an unweighted analysis using the log response ratio $(\ln R)$ to calculate bootstrapped confidence limits using the statistical software MetaWin 2.0 (Rosenberg et al., 2000) in order to include studies that did not report sample size or standard deviation. The response ratio $(R)$ is the ratio between the outcome of experimental group (i.e., $\bar{X}_{N T}$ ) to that of the control group (i.e., $\bar{X}_{C T}$ ) to estimate the proportional changes resulting from NT using a random model.

$$
R=\frac{\bar{X}_{N T}}{\bar{X}_{C T}}
$$


Using $\ln R$ instead of $R$ allows linearization of the metric, treating deviations in the numerator the same as deviations in the denominator since $\ln R=\ln \bar{X}_{N T}-\ln \bar{X}_{C T}$. Since ratio is more affected by denominator, using $R$ instead of $\ln R$ can generate disproportional rather than equal changes in either the numerator or denominator, especially when the denominator is small. Using $\ln R$ also allows a more normal distribution of samples, particularly when the number of samples is small, and minimizes the variability that occurred across different management strategies (Hedges et al., 1999). To improve the reliability of $\ln R$ in estimating the effect size of the response ratio, we performed a diagnostic test using the formula:

$$
\frac{\bar{x}}{S D}\left(\frac{4 N^{\frac{3}{2}}}{1+4 N}\right) \geq 3
$$

where $\bar{x}$ is the mean, $S D$ is the standard deviation and $N$ is the sample size (Lajeunesse, 2015). Bootstrapping was also iterated 9999 times to improve the probability that the confidence interval was calculated around the cumulative mean effect size for each categorical variable. The sample size and the number of studies of each bootstrapping are reported in each figure. The difference between NT and CT treatment is considered statistically significant if the $95 \%$ confidence interval (CI) does not overlap zero, while the difference between categorical variables is considered significant if the bootstrap CI does not overlap with each other. Statistical significance was determined at $P<0.05$ (Curtis and Wang, 1998; Lu et al., 2016).

\section{Results}

Although concentration and load provide a measure for P transfer from agricultural fields to adjacent water bodies (Fig. 1), our results showed that in many cases the two parameters exhibited different patterns (Figs. 2-3, Supplemental Figs. S1-S4). In general, NT management 
resulted in increased concentration and load of dissolved P, but significantly reduced the load and concentration of particulate and total P transferred to aquatic ecosystems (Fig. 1). There has been, however, a large variability on the effect of NT on P loss, and this variability is associated with several physical and management factors, including climate (dryland vs non-dryland), rainfall (wet vs dry year), transport pathway (leaching vs runoff), landscape topography (slope gradient), crop species (soybean, corn and wheat), and tillage duration (short vs medium).

\subsection{Physical factors}

Our results showed significantly greater dissolved P loss from NT in the dryland compared to the non-dryland regions. Similarly, NT was less effective in reducing particulate and total P load in the drylands than in the non-drylands (Supplemental Fig. S1). In accord with the overall results of the meta-analysis (Fig. 1), the concentration of dissolved P was also consistently higher with NT than with CT regardless of the transport pathway (runoff or leachate; Supplemental Fig. S2).

Different from the overall results (Fig. 1), we found that dissolved $\mathrm{P}$ concentration was generally similar under NT and CT during normal and dry years (i.e., the CI overlaps zero; Fig. 2a). Although NT generated significantly higher dissolved P concentration than CT during wet years (Fig. 2a), the difference in dissolved P load was not significant between the two tillage practices (i.e., the CI overlaps zero; Fig. 2b). In contrast to the overall meta-analysis results (Fig. 1), we also found that during wet years, there was no significant difference between NT and CT with respect to particulate P concentration (i.e., the CI overlaps zero; Fig. 2c). In other words, NT was more effective than CT in reducing particulate P concentration during normal and dry years, but not during wet years (Fig. 2c). 
Our results indicated that NT farming was most effective at reducing particulate P loss when slope gradient was in the 0-3\% range (Fig. 3d). On steeper slopes (4-9\%), there was no significant difference between NT and CT with respect to particulate P load (i.e., the CI overlaps zero; Fig. 3d). On steeper slopes, we also found similar concentration of dissolved P between NT and CT (i.e., the CI overlaps zero; Fig. 3a), but a significantly larger dissolved P load with NT (Fig. 3b).

\subsection{Management factors}

We found that dissolved P concentration did not differ from the overall meta-analysis results (Fig. 1), except for fields planted with corn in which dissolved P concentration and load with NT and CT were similar (Supplemental Figs. S3a and S3b). In contrast to the overall result (Fig. 1), NT failed to reduce the concentration of particulate and total P from fields planted with soybean (i.e., the CI overlaps zero; Supplemental Figs. S3c and S3e).

Although a general reduction in the concentration and load of total P was achieved with NT adoption (Fig. 1), these positive impacts seem to vanish with longer NT duration. No significant difference was found between CT and medium-term NT in terms of total P concentration and load (i.e., the CI overlaps zero; Supplemental Fig. S4), suggesting a possible effect of NT duration in determining the effectiveness of NT as a management strategy to control the diffuse loss of $\mathrm{P}$ in agricultural watersheds.

\section{Discussion}

Our analysis showed that, in assessing the impact of NT of soil P loss, different conclusions can be drawn depending on whether the assessment is made using $\mathrm{P}$ concentration or $\mathrm{P}$ load. 
Load of agricultural nutrients transported to surface and groundwater systems is more meaningful as load represents the mass of nutrients leaving an agro-ecosystem (Randall and Mulla, 2001). Although dissolved P, particularly orthophosphate, is the $\mathrm{P}$ fraction that directly causes eutrophication due to its immediate availability for biological uptake (Correll, 1998), particulate $\mathrm{P}$ can provide a long-term source of $\mathrm{P}$ to fuel biological processes in the receiving water bodies. Therefore, reduction in the concentration and load of particulate P may be one of the most important water quality benefits of NT farming as it helps mitigate the export of this form of P from agro-ecosystems. NT management has consistently been shown to reduce the amount of soil loss and sediment yield in dryland (Fu et al., 2006), temperate (Rhoton et al., 2002), and tropical regions (Lal, 1997). However, as noted in the introduction, the impact of NT on soil P loss can be modulated by several physical (e.g., rainfall variability, slope, and transport pathway) and management factors (crop species and NT duration).

\subsection{Climate regions and rainfall variability}

Climate determines the amount of water available to transport P from cultivated landscapes into surface water bodies (Randall and Mulla, 2001). The episodic nature of water availability in dryland regions can have significant consequences on $\mathrm{P}$ immobilization and mineralization (Austin et al., 2004), and our results suggest that these climatic attributes may have played a role in determining the effect of tillage on soil P mobility. Most specifically, our results showed that NT was less effective in controlling P loss (dissolved and particulate) in dryland than in nondryland regions (Supplemental Fig. S1).

In comparison to CT, NT soils are often characterized by higher SOM content, better soil moisture retention, and a larger and more active community of soil decomposers (Triplett and 
Dick, 2008). Taken together, these soil characteristics could translate into higher $\mathrm{P}$ mineralization and the resulting increase in dissolved $\mathrm{P}$ concentration in the surface layers of NT than CT under water-limited conditions. An increase in dissolved P concentration can be ascribed to greater rates of organic P mineralization in NT soils (compared to CT soils) subjected to repeated drying and moistening cycles (Austin et al., 2004; Burke et al., 1995; Butterly et al., 2009; Smith and Jacinthe, 2014; Wang et al., 2015). Past studies have also documented similar increases in soluble P flux following dry periods, and have linked these results to the greater solubility of phosphate minerals controlling P activity in the soil solution in post-drought periods (Smith and Jacinthe, 2014).

In addition to climate region, annual rainfall variability emerged as an important factor to understand the impact of tillage on P transport. An important finding of this meta-analysis is the observed increase in dissolved P load with NT during dry years. In order words, NT was generally not effective in controlling dissolved P loss (Fig. 1b), but was more so during dry years compared to wet or normal years (Fig. 2b). The exact mechanisms for the increase in dissolved $\mathrm{P}$ load during dry years remain to be elucidated, but could be the result of episodic increases in surface runoff and enhanced P mineralization in NT soils. Increased runoff during dry-wet cycling periods might be counterintuitive to explain, but could involve the formation of crusts (Valentin and Bresson 1992) and depositional surface seals that block macropores in NT soils (Assouline, 2011; King et al., 2015). Rapid soil moistening at the end of a dry period may also cause the collapse of macropore walls (Vendelboe et al., 2011). As a result, water infiltration can be impeded and significant amount of runoff can thus be generated during the first rainfall events following a prolonged dry period, even on soils that would otherwise exhibit high infiltration 
capacity. Lending support to this proposition is the disproportionally lower total P load via subsurface transport during dry years than wet years (King et al., 2015).

The decrease in P retention efficiency of NT soils during dry years is an important finding with implications for our ability to project trends in water quality in relationship to climate and agriculture. A greater frequency of dry-wet cycle is predicted for several world eco-regions, including the United States Corn Belt (Mishra et al., 2010). If these projections are correct, it seems therefore that NT farming would be inadequate to protect water quality, at least in terms of mitigating P export from croplands. Thus, NT needs to be augmented with other suitable practices such as cover crops, reduced $\mathrm{P}$ application rate, injection of liquid P-fertilizer to minimize dissolved P export (leaching and runoff) to streams and rivers.

\subsection{Transport pathway}

We found that the concentration of dissolved $\mathrm{P}$ through leaching and runoff did not differ from the overall results of the meta-analysis (Supplemental Fig. S2). Although our discussion of P leaching pathways is constrained by data availability, our results are consistent with a review conducted for Scandinavian soils that showed: (i) a reduction in total P loss with NT through both runoff and leaching, but (ii) a four-fold increase in dissolved P loss with NT compared to CT (Ulén et al., 2010). High dissolved P concentration in surface runoff could be due to limited vertical movement of fertilizer-P in NT soils, as well as minimum mixing between soil, crop residue, and surface-applied P fertilizers (Bordoli and Mallarino, 1998; Zibilske et al., 2002). Combined with increased soil compaction under long-term NT (Ferreras et al., 2000), P accumulation in the surface soil layers could markedly increase the potential for loss (Holland, 2004). Given the lower P sorption capacity of surface soils under NT (Bordoli and Mallarino, 1998), and the common practice of broadcast P-fertilizer application, it is unsurprising that NT 
practice is inefficient at controlling dissolved P loss. However, NT generally leads to substantial reduction in runoff volume (Huggins and Reganold, 2008), and this may have contributed to the lower load of particulate and total P (Fig. 1).

Previous studies have identified macropores as a major pathway of P leaching loss (King et al., 2015; Williams et al., 2016). The development of macropores in NT soils (e.g., earthworm burrows and dead roots of previous crops) provides a conduit for the rapid vertical transport of $\mathrm{P}$ in cultivated fields (Williams et al., 2016). In plowed soils, this pathway is far less significant due to destruction of macropores during plowing operations. A recent review suggested that $\mathrm{P}$ discharge associated with macropores flow could account for $>50 \%$ of the annual dissolved $\mathrm{P}$ loss via leaching (King et al., 2015).

\subsection{Slope}

Our results showed greater concentration of dissolved P with NT compared to CT on flat landscapes ( $<3 \%$ slope), but similar concentration in relatively steep terrains (Fig. 3a). Surface accumulation (stratification) of $\mathrm{P}$ and decreased $\mathrm{P}$ sorption capacity are well-documented characteristics of soils under NT (Bordoli and Mallarino, 1998; Holland, 2004). On flat landscapes, one can easily envision how interactions of rainwater with NT soil surface could promote $\mathrm{P}$ desorption and give rise to elevated concentrations of dissolved $\mathrm{P}$ in surface waters (Fig. 3a). Such an outcome is more likely in NT soils with high STP (or after recent P application) even when erosion is kept at a minimum (Penn et al., 2005).

Studies have shown that the presence of crop residue on NT soil surface acts as a physical barrier to lateral transport of water and soil particles (Adekalu et al., 2007; Quinton and Catt 2004). Although this land surface condition helps explain the efficiency of NT in controlling 
particulate P loss on relatively gentle slopes, its efficacy diminishes on steeper slopes (Fig. 3d). In addition to chemical desorption, P loss can also be controlled by soil erosion and runoff. As these physical processes become more important as slopes become steeper, a significant amount of P, including dissolved P can be transported via runoff (Penn et al., 2005). These processes could help explain the similar concentration of dissolved P measured under CT and NT with increased landscape declivity (Fig. 3a).

\subsection{Crop species}

Elevated dissolved P concentration and load with wheat (Supplemental Figs. S3a, S3b) could be attributed to a reduction in $\mathrm{P}$ uptake and subsequent increase of residual soil P. The recovery of fertilizer P by monoculture winter wheat tends to decrease with continuous fertilizer application (Sharpley, 1986). Furthermore, it has been shown that, unlike corn, P fertilizer application did not affect wheat grain P content (Tang et al., 2008), suggesting that wheat may have low P uptake. Therefore, the pool of available soil P can be high following harvest of a wheat crop. All of our data came from fields under winter wheat where $\mathrm{P}$ application before fall planting was a common practice; therefore, the practice may have additionally contributed to the high dissolved P loss associated with this crop.

Similarly, lower P uptake by soybean (compared to corn) may have also contributed to greater dissolved P concentration from soybean than from corn fields (Supplemental Fig. S3a), despite comparable rates of fertilizer P application to both crops (Gaynor and Findlay, 1995; Schreiber and Cullum, 1998; Eghball et al., 2003). The common rate of P fertilizer application to cropland in North America and Canada (45 kg P ha ${ }^{-1}$ year $\left.^{-1}\right)$ may be excessive in NT systems given that only 31-67\% of applied P is incorporated into crop biomass (Carefoot and Whalen, 
2003). Limited sorption of fertilizer $P$ in the absence fertilizer incorporation under NT further increases the risk for P loss. Indeed, soluble P concentration in runoff from NT fields planted to soybean $\left(0.4 \mathrm{mg} \mathrm{L}^{-1}\right)$ was 20 -times higher than from CT soybean fields $\left(0.02 \mathrm{mg} \mathrm{L}^{-1}\right)$ where $\mathrm{P}$ fertilizer was incorporated (McDowell and McGregor, 1980). Therefore, light occasional surface tillage of NT fields following fertilizer P application could be an approach worth considering in order to reduce surface $\mathrm{P}$ accumulation and elevated $\mathrm{P}$ concentration in runoff. Rotation with perennial crops with high P uptake potential (Cavigelli and Thien, 2003) could also be considered as a complementary management to scavenge residual soil P after harvest.

\subsection{Tillage duration}

Studies have shown a general increase in nutrient concentration with NT, including P, particularly in the top $5 \mathrm{~cm}$ soil layer (e.g., Essington and Howard, 2000; Howard et al., 1999). This P accumulation could lead to saturation P fixation sites (Guertal et al., 1999), resulting in lower P retention capacity. In addition to soil compaction and increased bulk density (Messiga et al., 2010), surface P stratification may have contributed to the observed increase in P loss with longer NT duration (Supplemental Fig. S4). Since long-term NT contributes to soil health and soil erosion reduction, it can provide a foundation for a sustainable management of agricultural soils (Montgomery, 2007). However, NT should be combined with other management practices in order to reduce the amount of dissolved P loss.

\section{Conclusions}

Our results indicated that NT, through its impact on soil properties (organic matter, water retention, soil compaction) and surface $\mathrm{P}$ stratification, co-varies with climatic, landscape and 
management factors in determining $\mathrm{P}$ loss from agricultural soils. Specifically, results of our meta-analysis showed that NT can effectively reduce the amount and concentration of particulate $\mathrm{P}$ in agricultural catchment waters, but not dissolved P. In light of these findings, we recommend a combination of NT with other land management techniques (e.g., injection instead of broadcast application of $\mathrm{P}$ fertilizer, inclusion of cover crops to scavenge residual $\mathrm{P}$, intercropping or rotation with perennial crops) to improve NT performance with regard to the export of dissolved P. Given the pronounced surface stratification of soil P under long-term NT, occasional soil harrowing (i.e., once in 10 or more years) may help overcome some of the problems observed with NT (e.g., surface P accumulation, compaction particularly in fine-textured soils) without causing significant soil quality deterioration (Quincke et al., 2007). Light mixing of (organic) fertilizer when applied to NT fields should also be considered since the practice was found to significantly decrease P loss (Kleinman et al., 2002; Kleinman et al., 2009; Williams et al., 2016). Finally, the installation and restoration of wetlands downslope from agricultural fields may be beneficial, although wetlands tend to be more efficient at retaining particulate than dissolved P (Hoffmann et al., 2009).

\section{Acknowledgements}

This research was supported by a postdoctoral fellowship from Schlumberger Foundation, and by the National Institute of Food and Agriculture (NIFA/USDA), grant No. 2014-51130-22492. We thank the editors (Dr. Ed Gregorich, Dr. Peter Kleinman and Dr. Casey Kennedy) and the anonymous reviewers for their insightful comments and constructive suggestions to improve the quality of this manuscript. 


\section{References}

Agriculture and Agri-Food Canada. 2013. http://sis.agr.gc.ca/cansis/nsdb/slc/v3.2/cmp/

slope.html. Accessed February 1, 2017.

Adekalu, K.O., I.A. Olorunfemi, and J.A. Osunbitan. 2007. Grass mulching effect on infiltration, surface runoff and soil loss of three agricultural soils in Nigeria. Bioresour. Technol. 98: 912917.

Al-Kaisi, M.M., and X. Yin. 2004. Stepwise time response of corn yield and economic return to no tillage. Soil Tillage Res. 78: 91-101.

Amon-Armah, F., E.K. Yiridoe, N.H. Ahmad, D. Hebb, R. Jamieson, D. Burton, et al. 2013. Effect of nutrient management planning on crop yield, nitrate leaching and sediment loading in Thomas Brook Watershed. Environ. Manage. 52: 1177-1191.

Assouline, S. 2011. Soil Surface Sealing and Crusting. In: J. Glinski et al., editors, Encyclopedia of Agrophysics. Springer Netherlands, p. 786-791.

Austin, A.T., L. Yahdijan, J.M. Stark, J. Belnap, A. Porporato, U. Norton, et al. 2004. Water pulses and biogeochemical cycles in arid and semiarid ecosystems. Oecologia 141: 221-235. Bennett, E.M., S.R. Carpenter, and N.F. Caraco. 2001. Human impact on erodable phosphorus and eutrophication: a global perspective increasing accumulation of phosphorus in soil threatens rivers, lakes, and coastal oceans with eutrophication. BioSci. 51: 227-234.

Bordoli, J.M., and A.P. Mallarino. 1998. Deep and shallow banding of phosphorus and potassium as alternatives to broadcast fertilization for no-till corn. Agron. J. 90: 27-33.

Burke, I.C., E.T. Elliot, and C.V. Cole. 1995. Influence of macroclimate, landscape position, and management on soil organic matter in agroecosystems. Ecol. Appl. 5: 124-131. 
Butterly, C.R., E.K. Bünemann, A.M. McNeill, J.A. Baldock, and P. Marschner. 2009. Carbon pulses but not phosphorus pulses are related to decreases in microbial biomass during repeated drying and rewetting of soils. Soil Biol. Biochem. 41: 1406-1416.

Carefoot, J., and J. Whalen. 2003. Phosphorus concentrations in subsurface water as influenced by cropping systems and fertilizer sources. Can. J. Soil Sci. 83: 203-212.

Cavigelli, M.A., and S.J. Thien. 2003. Phosphorus bioavailability following incorporation of green manure crops. Soil Sci. Soc. Am. J. 67: 1186-1194.

Conley, D.J., H.W. Paerl, R.W. Howarth, D.F. Boesch, S.P. Seitzinger, E. Karl, et al. 2009. Controlling eutrophication: nitrogen and phosphorus. Science 123: 1014-1015.

Correll, D.L. 1998. The role of phosphorus in the eutrophication of receiving waters: A review. J. Environ. Qual. 27: 261-266.

Curtis, P.S., and X. Wang. 1998. A meta-analysis of elevated $\mathrm{CO}_{2}$ effects on woody plant mass, form, and physiology. Oecologia 113: 299-313.

Daryanto, S., L. Wang, and P.A. Jacinthe. 2016. Drought effects on root and tuber production: A meta-analysis. Agric. Water Manage. 176: 122-131.

Daryanto, S., L. Wang, and P.A. Jacinthe. 2017. Global synthesis of drought effects on cereal, legume, tuber and root crops production: A review. Agric. Water Manage. 179: 18-33.

Dodd, J.R., and A.P. Mallarino. 2005. Soil-test phosphorus and crop grain yield responses to long-term phosphorus fertilization for corn-soybean rotations. Soil Sci. Soc. Am. J. 69: 11181128.

Dumanski, J., R. Pieretti, J.R. Benites, D. McGarry, and C. Pieri. 2006. The paradigm of conservation agriculture. Proceedings of World Association of Soil and Water Conservation. P1: 58-64. 
Eghball, B., J.F. Shanahan, G.E. Varvel, and J.E. Gilley. 2003. Reduction of high soil test phosphorus by corn and soybean varieties. Agron. J. 95: 1233-1239.

Essington, M.E., and D.D. Howard. 2000. Phosphorus availability and speciation in long-term no-till and disk-till soil. Soil Sci. 165, 144-152.

FAO. 2012. Twenty most important food and agricultural commodities. http://faostat.fao.org/site/339/default.aspx. Accessed June 15, 2015.

Ferreras, L., J. Costa, F. Garcia, and C. Pecorari. 2000. Effect of no-tillage on some soil physical properties of a structural degraded Petrocalcic Paleudoll of the southern "Pampa" of Argentina. Soil Tillage Res. 54: 31-39.

Francis, G., and T. Knight. 1993. Long-term effects of conventional and no-tillage on selected soil properties and crop yields in Canterbury, New Zealand. Soil Tillage Res. 26: 193-210.

Fu, G., S. Chen, and D.K. McCool. 2006. Modeling the impacts of no-till practice on soil erosion and sediment yield with RUSLE, SEDD, and ArcView GIS. Soil Tillage Res. 85: 38-49.

Gaynor, J., and W. Findlay. 1995. Soil and phosphorus loss from conservation and conventional tillage in corn production. J. Environ. Qual. 24: 734-741.

Guertal, E.A., D.J. Eckert, S.J. Traina, and T.J. Logan. 1999. Differential phosphorus retention in soil profiles under no-till crop production. Soil Sci. Soc. Am. J. 55: 410-413.

Hedges, L.V., J. Gurevitch, and P.S. Curtis. 1999. The meta-analysis of response ratios in experimental ecology. Ecology 80: 1150-1156.

Hisdal, H., L. Tallaksen, E. Peters, K. Stahl, and M. Zaidman. 2000. Drought Event Definition. In: H. Hisdal and L. Tallaksen, editors, ARIDE Technical Report. Department of Geophysics, University of Oslo, Oslo, Norway. 
Hoffmann, C.C., C. Kjaergaard, J. Uusi-Kämppä, H.C.B. Hansen, and B. Kronvang. 2009. Phosphorus retention in riparian buffers: review of their efficiency. J. Environ. Qual. 38: 19421955.

Holland, J. 2004. The environmental consequences of adopting conservation tillage in Europe: reviewing the evidence. Agr. Ecosyst. Environ. 103: 1-25.

Horowitz, J., Ebel, R., and K. Ueda. 2010. No-till farming is a growing practice. Economic Information Bulletin No. 70. United States Department of Agriculture.

Howard, D.D., M.E. Essington, and D.D. Tyler. 1999. Vertical phosphorus and potassium stratification in no-till cotton soils. Agron. J. 91: 266-269.

Huggins, D.R., and J.P. Reganold. 2008. No-till: the quiet revolution. Sci. Am. 299: 70-77. Jarvie, H.P., J. Withers, and C. Neal. 2002. Review of robust measurement of phosphorus in river water: sampling, storage, fractionation and sensitivity. Hydrol. Earth Syst. Sci Discuss. 6: 113-131.

King, A.W., M.R. Williams, M.L. Macrae, N.R. Fausey, J. Frankenberger, D.R. Smith, et al. 2015. Phosphorus transport in agricultural subsurface drainage. J. Environ. Qual. 44: 467-485. Kleinman, P.J., A.N. Sharpley, B.G. Moyer, and G.F. Elwinger. 2002. Effect of mineral and manure phosphorus sources on runoff phosphorus. J. Environ. Qual. 31: 2026-2033.

Kleinman, P.J., A.N. Sharpley, L.S. Saporito, A.R. Buda, and R.B. Bryant. 2009. Application of manure to no-till soils: phosphorus losses by sub-surface and surface pathways. Nutr. Cycling Agroecosyst. 84: 215-227.

Lajeunesse, M. 2015. Bias and correction for the log response ratio in ecological metaanalysis. Ecology 96: 2056-2063. 
Lal, R. 1997. Soil degradative effects of slope length and tillage methods on alfisols in western Nigeria. I. Runoff, erosion and crop response. Land Degrad. Dev. 8: 201-219.

Lu, X., L. Wang, and M.F. McCabe. 2016. Elevated $\mathrm{CO}_{2}$ as a driver of global dryland greening. Sci. Rep. 6: 20716. doi:10.1038/srep20716.

McDowell, L., and K. McGregor. 1980. Nitrogen and phosphorus losses in runoff from no-till soybeans. Trans. ASAE 23: 643-0648.

Messiga, A.J., N. Ziadi, C. Morel, and L.E. Parent. 2010. Soil phosphorus availability in no-till versus conventional tillage following freezing and thawing cycles. Can. J. Soil Sci. 90: 419-428. Mishra, V, K.A. Cherkauer, and S. Shukla. 2010. Assessment of drought due to historic climate variability and projected future climate change in the midwestern United States. J.

Hydrometeorol. 11: 46-68.

Montgomery, D.R. 2007. Soil erosion and agricultural sustainability. Proc. Natl. Ac. Sci. 104: 13268-13272.

Ogle, S.M., A. Swan, and K. Paustian. 2012. No-till management impacts on crop productivity, carbon input and soil carbon sequestration. Agr. Ecosyst. Environ. 149: 37-49.

Penn, C.J., G.L. Mullins, and L.W. Zelazny. 2005. Mineralogy in relation to phosphorus sorption and dissolved phosphorus losses in runoff. Soil Sci. Soc. Am. J. 69: 1532-1540.

Quincke, J., C. Wortmann, M. Mamo, T. Franti, and R. Drijber. 2007. Occasional tillage of notill systems. Agron. J. 99: 1158-1168.

Quinton, J.N., and J.A. Catt. 2004. The effects of minimal tillage and contour cultivation on surface runoff, soil loss and crop yield in the long-term Woburn Erosion Reference Experiment on sandy soil at Woburn, England. Soil Use Manage. 20, 343-349. 
Randall, G.W., and D.J. Mulla. 2001. Nitrate nitrogen in surface waters as influenced by climatic conditions and agricultural practices. J. Environ. Qual. 30: 337-344.

Rhoton, F., M. Shipitalo, and D. Lindbo. 2002. Runoff and soil loss from midwestern and southeastern US silt loam soils as affected by tillage practice and soil organic matter content. Soil Tillage Res. 66: 1-11.

Rosenberg, M.S., D.C. Adams, and J. Gurevitch. 2000. Metawin: Statistical Software for Metaanalysis, Version 2.1. Sinauer Associates, Inc., Sunderland, MA, USA.

Schreiber, J., and R. Cullum. 1998. Tillage effects on surface and groundwater quality in loessial upland soybeanwatersheds. Trans. ASAE 41: 607-614.

Sharpley, A. 1986. Disposition of fertilizer phosphorus applied to winter wheat. Soil Sci. Soc. Am. J. 50: 953-958.

Smith, A.S., and P.A. Jacinthe. 2014. A mesocosm study of the effects of wet-dry cycles on nutrient release from constructed wetlands in agricultural landscape. Environ. Sci.: Processes Impact. 16: 106-115.

Tang, X., J. Li, Y. Ma, X. Hao, and X. Li. 2008. Phosphorus efficiency in long-term (15 years) wheat-maize cropping systems with various soil and climate conditions. Field Crops Res. 108: 231-237.

Triplett, G., and W.A. Dick. 2008. No-tillage crop production: A revolution in agriculture! Agron. J. 100: S-153-S-165.

Ulén, B., H. Aronsson, M. Bechmann, T. Krogstad, L. Ǿygarden, and M. Stenberg. Soil tillage methods to control phosphorus loss and potential side effects: A Scandinavian review. Soil Use Manage. 26: 94-107 
Vendelboe, A.L., P. Moldrup, G. Heckrath, Y. Jin, and L.W. de Jonge. 2011. Colloid and phosphorus leaching from undisturbed soil cores sampled along a natural clay gradient. Soil Sci. 176: 399-409.

Valentin, C., and L.M. Bresson. 1992. Morphology, genesis and classification of surface crusts in loamy and sandy soils. Geoderma 55: 225-245.

Wang, L., Manzoni, S., Ravi, S., Riveros-Iregui, D., and Caylor, K. 2015. Dynamic interactions of ecohydrological and biogeochemical processes in water-limited systems. Ecosphere 6: 1-27. Williams, M.R., K.W. King, W. Ford, A.R. Buda, and C.D. Kennedy. 2016. Effect of tillage on macropore flow and transport to tile drains. Water Resour. Res. 52: 2868-2882.

Zhou, Q., S. Daryanto, X. Zhiming, L. Zhimin, L. Minghu, C. Xue, et al. 2017. Soil phosphorus budget in global grasslands and implications for management. J. Arid Environ. 144: 224-235. Zibilske, L., J. Bradford, and J. Smart. 2002. Conservation tillage induced changes in organic carbon, total nitrogen and available phosphorus in a semi-arid alkaline subtropical soil. Soil Tillage Res. 66: 153-163. 


\section{Figure captions}

Fig. 1. Percentage change in the concentration (a) and load (b) of dissolved, particulate and total (dissolved + particulate) P with no-till (NT) in comparison to conventional tillage (CT). Black dots represent the mean of $\ln R$ with error bar representing the $95 \%$ confidence interval (CI). A negative value indicates a reduction due to NT adoption in comparison to CT, which is only statistically significant when the CI does not overlap zero. Letter ' $n$ ' indicates the number of samples, while the number of studies is reported in parentheses. The $P$ values indicate the statistical difference between categorical variables.

Fig. 2. Percentage change in the concentration and load of dissolved P (a-b) and the concentration of particulate P (c) with different rainfall variability. Black dots represent the mean of $\ln R$ with error bar representing the $95 \%$ confidence interval (CI). A negative value indicates a reduction due to NT adoption in comparison to CT, which is only statistically significant when the CI does not overlap zero. Letter ' $n$ ' indicates the number of samples, while the number of studies is reported in parentheses. The $P$ values indicate the statistical difference between categorical variables.

Fig. 3. Percentage change in the concentration and load of dissolved P (a-b) and particulate P (cd) with different slope. Black dots represent the mean of $\ln R$ with error bar representing the 95\% confidence interval (CI). A negative value indicates a reduction due to NT adoption in comparison to CT, which is only statistically significant when the CI does not overlap zero. Letter ' $n$ ' indicates the number of samples, while the number of studies is reported in parentheses. The $P$ values indicate the difference between categorical variables. 
Table 1. List of publications used to collect the database for this study.

\begin{tabular}{|c|c|c|c|c|c|c|}
\hline Author and year of publication $\dagger$ & $\begin{array}{c}\text { Dissolved P } \\
\text { concentration }\end{array}$ & $\begin{array}{c}\text { Particulate P } \\
\text { concentration }\end{array}$ & $\begin{array}{c}\text { Total P } \\
\text { concentration }\end{array}$ & $\begin{array}{c}\text { Dissolved P } \\
\text { load }\end{array}$ & $\begin{array}{c}\text { Particulate P } \\
\text { load }\end{array}$ & Total P load \\
\hline Andraski et al. 1985 & $\mathrm{X} \ddagger$ & $\mathrm{X}$ & $\mathrm{X}$ & $\mathrm{X}$ & $\mathrm{X}$ & $\mathrm{X}$ \\
\hline Andraski et al. 2003 & $\mathrm{X}$ & $\mathrm{X}$ & $\mathrm{X}$ & $\mathrm{X}$ & $\mathrm{X}$ & $\mathrm{X}$ \\
\hline Bertol et al. 2007 & $\mathrm{X}$ & $\mathrm{X}$ & $\mathrm{X}$ & & & \\
\hline Blevins et al. 1990 & & & & $\mathrm{X}$ & & \\
\hline Brye et al. 2002 & $\mathrm{X}$ & & & $\mathrm{X}$ & & \\
\hline Brye and Norman 2004 & & & $\mathrm{X}$ & & & $\mathrm{X}$ \\
\hline Bundy et al. 2001 & $\begin{array}{l}\mathrm{X} \text { (dissolved } \\
\text { reactive } \mathrm{P} \text { or } \\
\mathrm{DRP})\end{array}$ & & $\mathrm{X}$ & $\begin{array}{l}\mathrm{X} \text { (dissolved } \\
\text { reactive } \mathrm{P} \text { or } \\
\mathrm{DRP})\end{array}$ & & $\mathrm{X}$ \\
\hline Chichester and Richardson 1992 & & & & $\mathrm{X}$ & & \\
\hline Daverede et al. 2003 & $\mathrm{X}$ & & & $\mathrm{X}$ & & \\
\hline Douglas-Mankin et al. 2010 & & & & $\mathrm{X}$ & & \\
\hline Gaynor and Findlay 1995 & $\mathrm{X}$ (Ortho-P) & $\mathrm{X}$ & & $\mathrm{X}$ (Ortho-P) & $\mathrm{X}$ & \\
\hline Kimmel et al. 2001 & & & & $\mathrm{X}$ & $\mathrm{X}$ & $\mathrm{X}$ \\
\hline Lal et al. 1997 & $\mathrm{X}$ & & & & & \\
\hline Lindau et al. 2010 & & & & $\mathrm{X}$ & & \\
\hline McIsaac et al. 1991 & $\mathrm{X}$ & & & $\mathrm{X}$ & & \\
\hline McIsaac et al. 1995 & $\mathrm{X}$ & & & $\mathrm{X}$ & & \\
\hline Puustinen et al. 2005 & $\mathrm{X}(\mathrm{DRP})$ & $\mathrm{X}$ & & $\mathrm{X}$ & $\mathrm{X}$ & \\
\hline Richardson and King 1995 & & & & $\mathrm{X}$ & & \\
\hline Schreiber and Cullum 1998 & $\mathrm{X}\left(\mathrm{PO}_{4}-\mathrm{P}\right)$ & $\mathrm{X}$ & & $\mathrm{X}\left(\mathrm{PO}_{4}-\mathrm{P}\right)$ & $\mathrm{X}$ & \\
\hline Sharpley and Smith 1994 & $\mathrm{X}$ & $\mathrm{X}$ & $\mathrm{X}$ & & & \\
\hline Sharpley 1995 & $\mathrm{X}$ & $\mathrm{X}$ & $\mathrm{X}$ & $\mathrm{X}$ & $\mathrm{X}$ & $\mathrm{X}$ \\
\hline Sharpley et al. 1995 & $\mathrm{X}$ & $\mathrm{X}$ & $\mathrm{X}$ & $\mathrm{X}$ & $\mathrm{X}$ & $\mathrm{X}$ \\
\hline Sharpley et al. 2015 & $\mathrm{X}$ & $\mathrm{X}$ & $\mathrm{X}$ & & & \\
\hline Shipitalo et al. 2013 & $\mathrm{X}$ & & & & & \\
\hline Smith et al. 1991 & $\mathrm{X}$ & $\mathrm{X}$ & $\mathrm{X}$ & $\mathrm{X}$ & $\mathrm{X}$ & $\mathrm{X}$ \\
\hline Wang et al. 2015 & $\mathrm{X}$ & $\mathrm{X}$ & $\mathrm{X}$ & & & $\mathrm{X}$ \\
\hline Zeimen et al. 2006 & $\mathrm{X}$ & $\mathrm{X}$ & $X$ & $\mathrm{X}$ & $\mathrm{X}$ & $\mathrm{X}$ \\
\hline
\end{tabular}


The full reference of the article is provided in Supplemental Material S1

$3 \ddagger \mathrm{X}$ mark indicates that data are available from the corresponding publication 

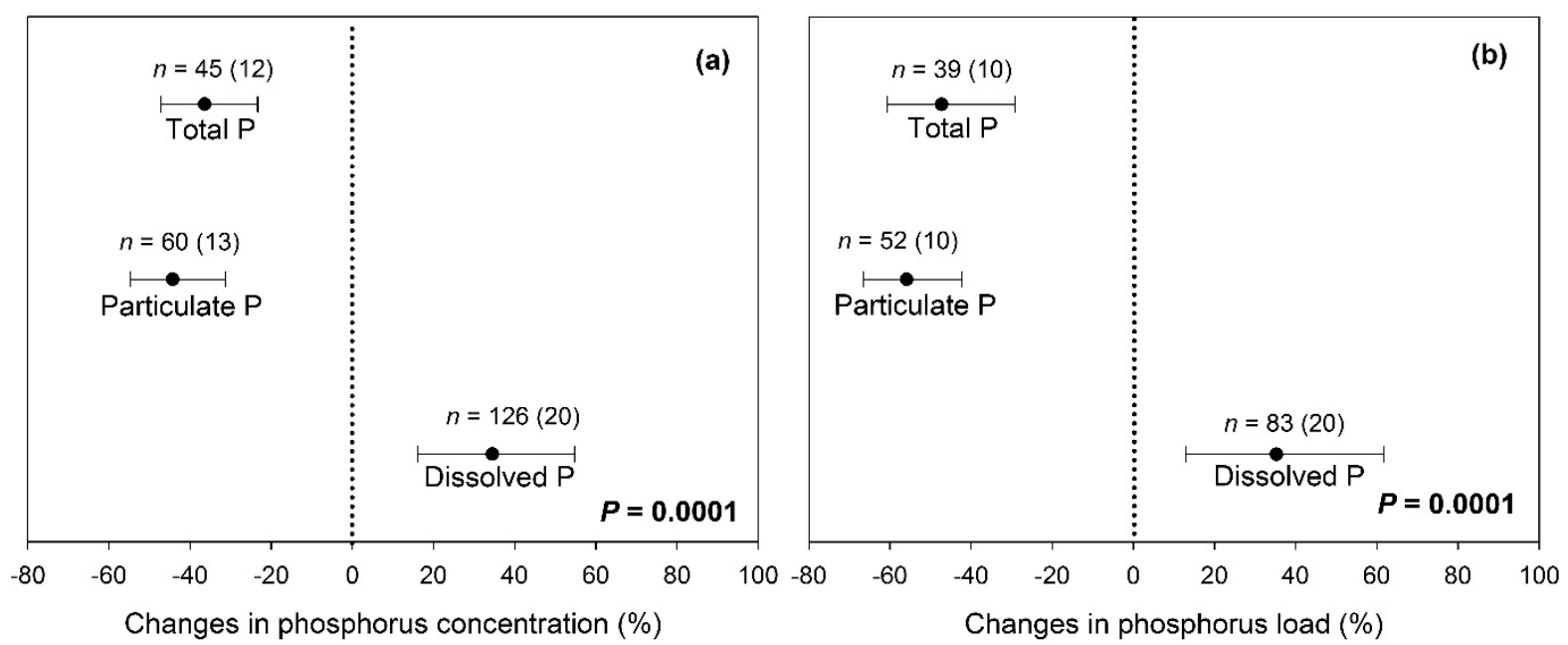

Fig. 1. The overall trend

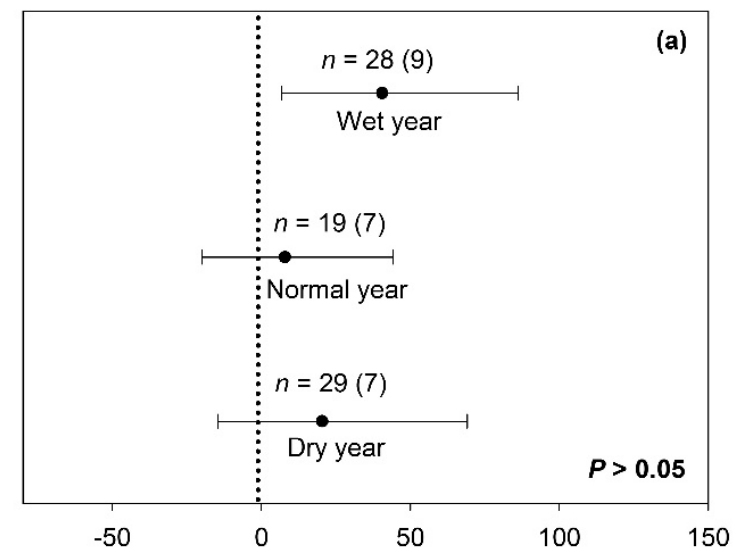

Changes in dissolved $\mathrm{P}$ concentration (\%)
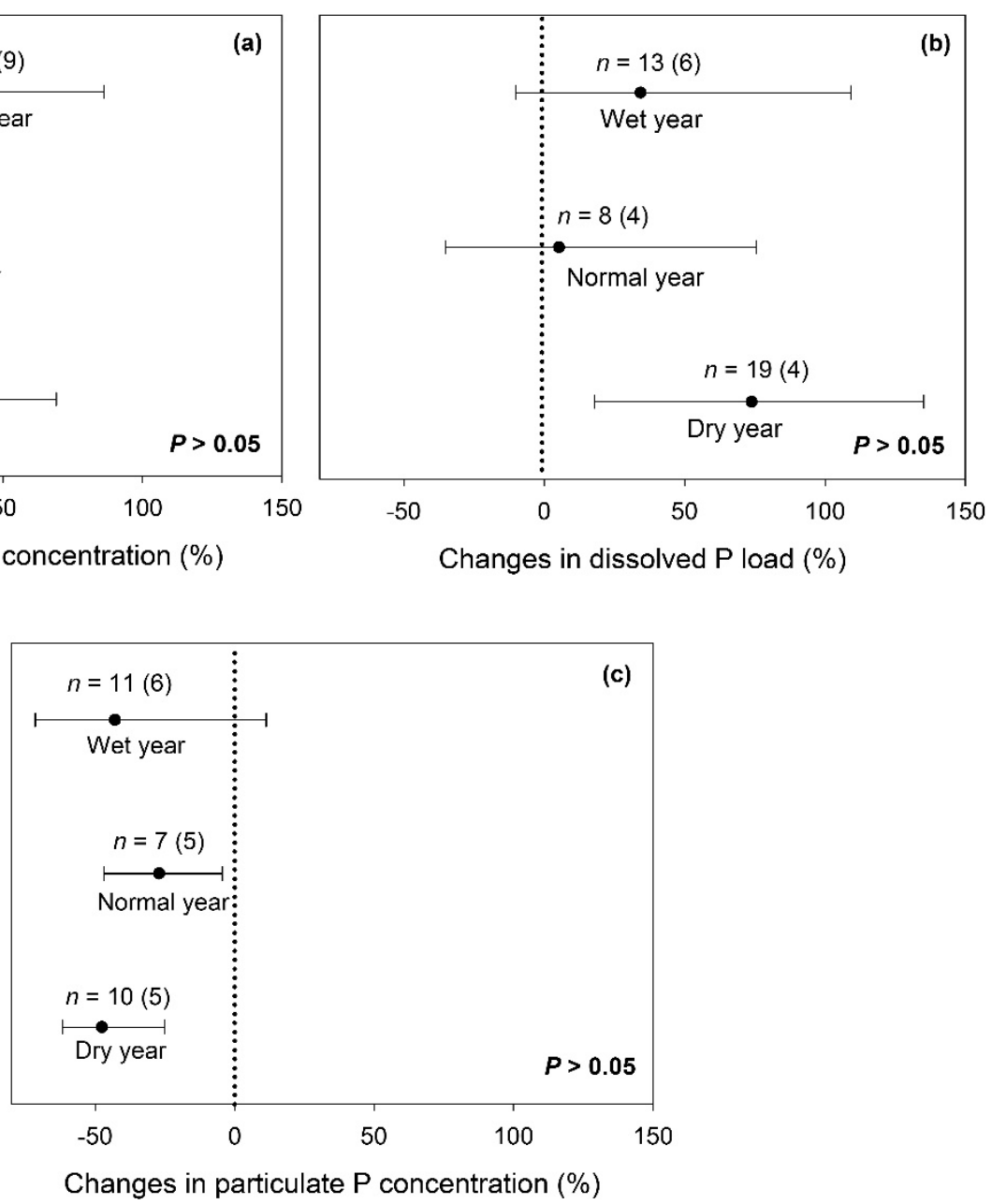

Fig. 2. Hydrological conditions 

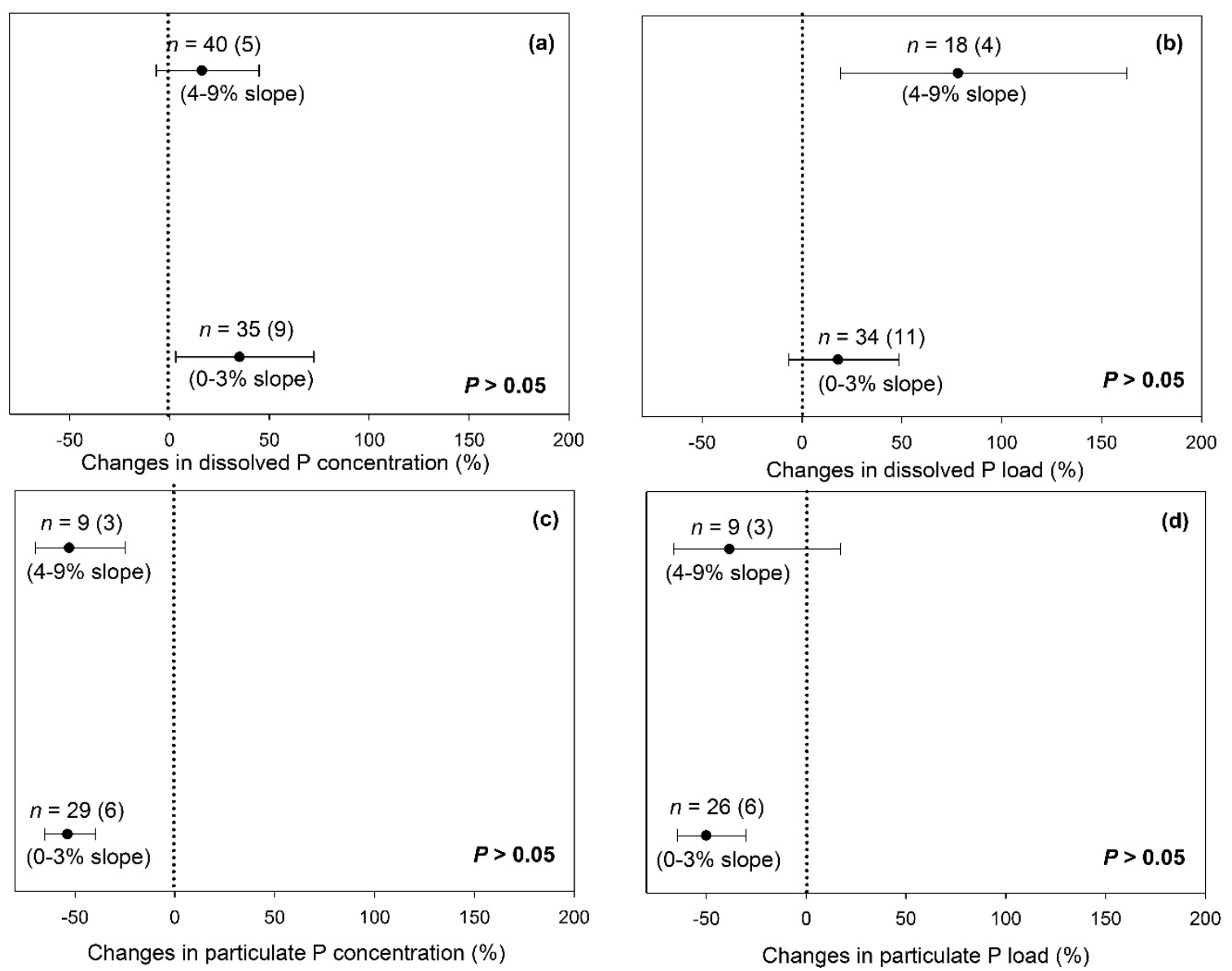

Fig. 3. Slope 

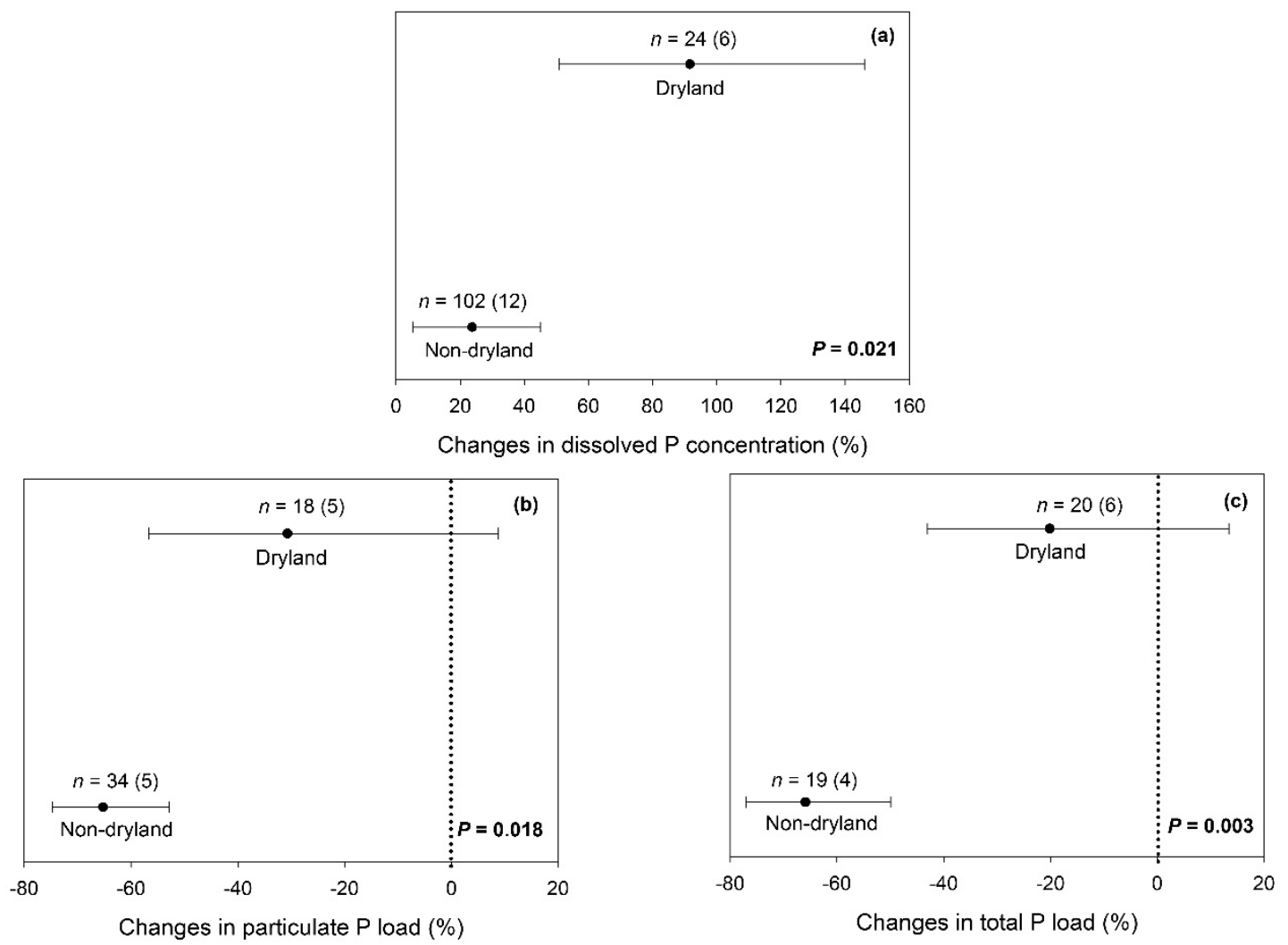

Suppl. Fig. S1

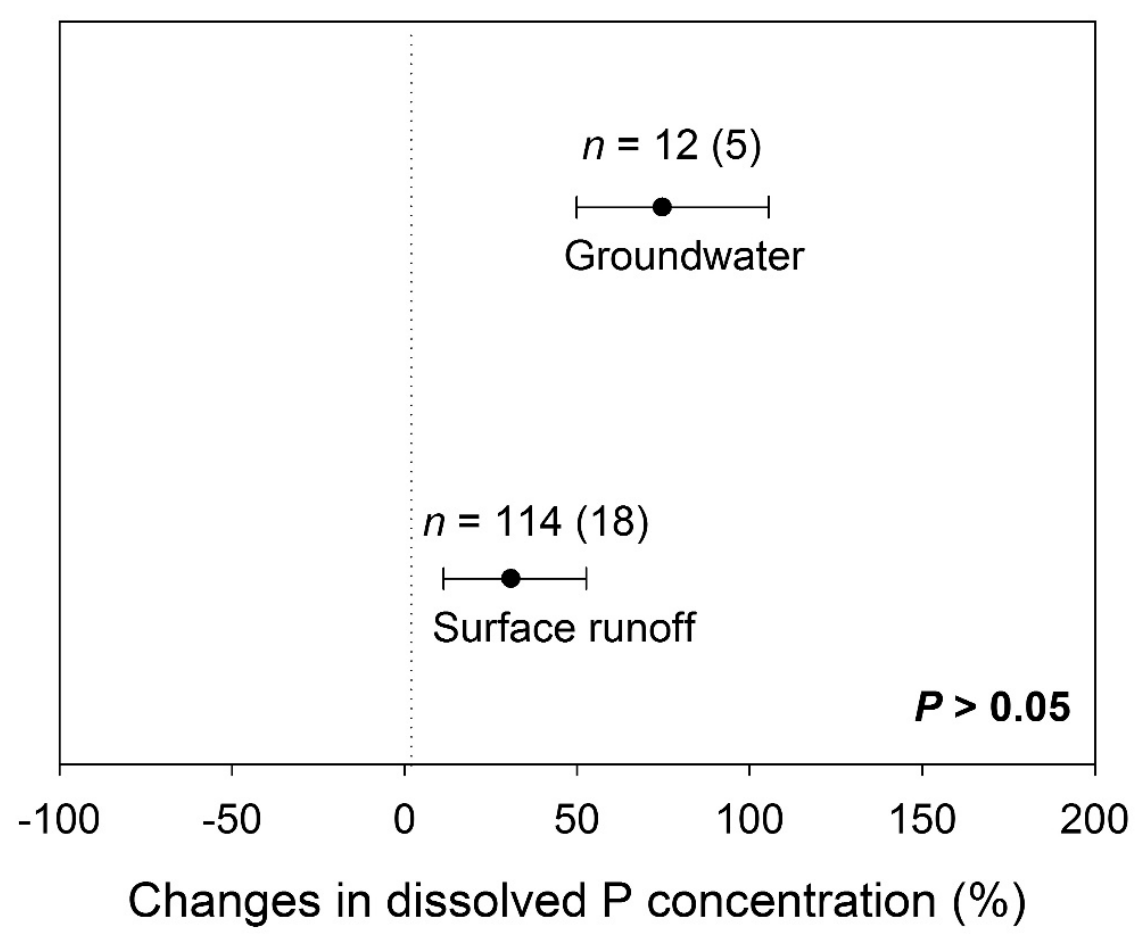

Suppl. Fig. S2 

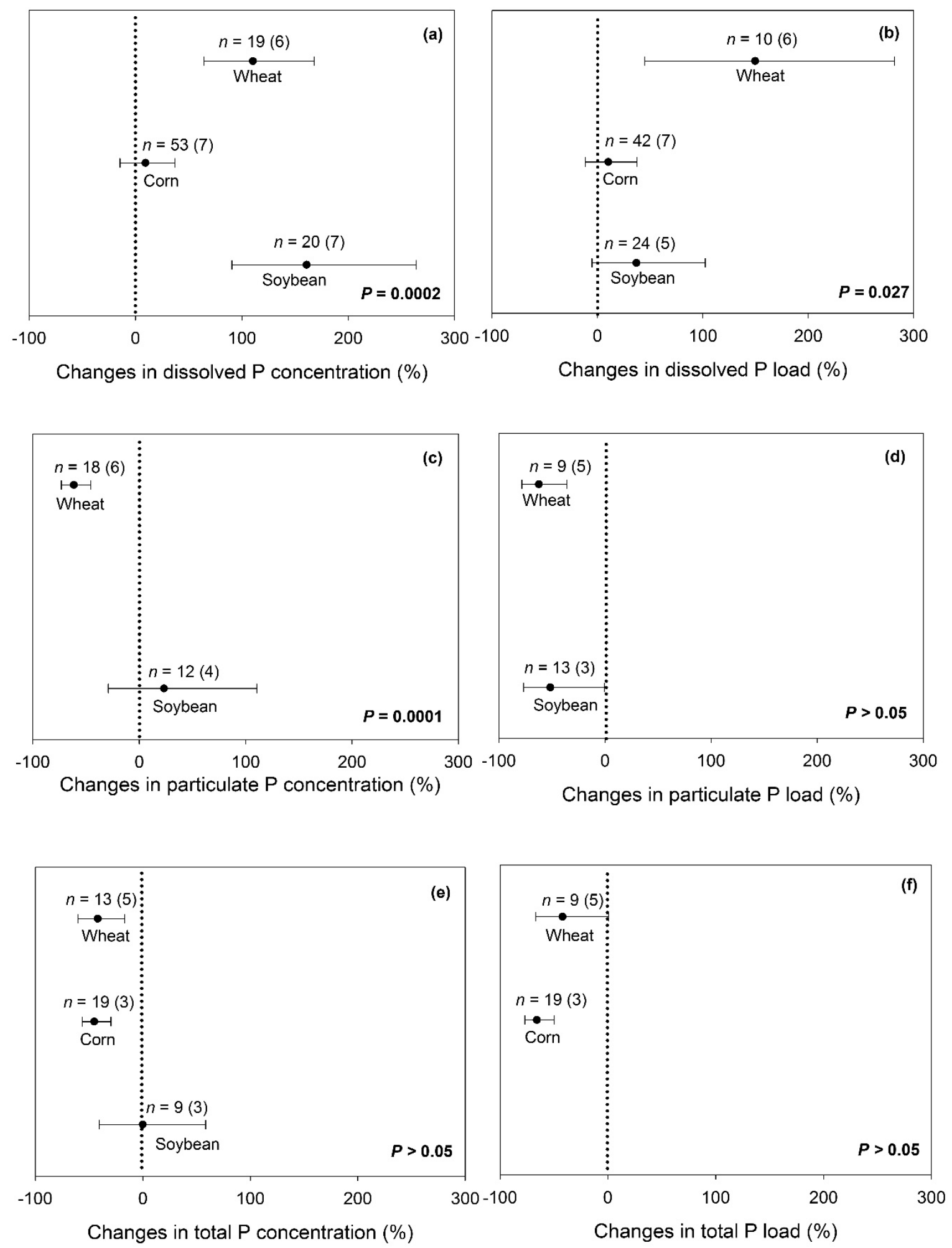

Suppl. Fig. S3 

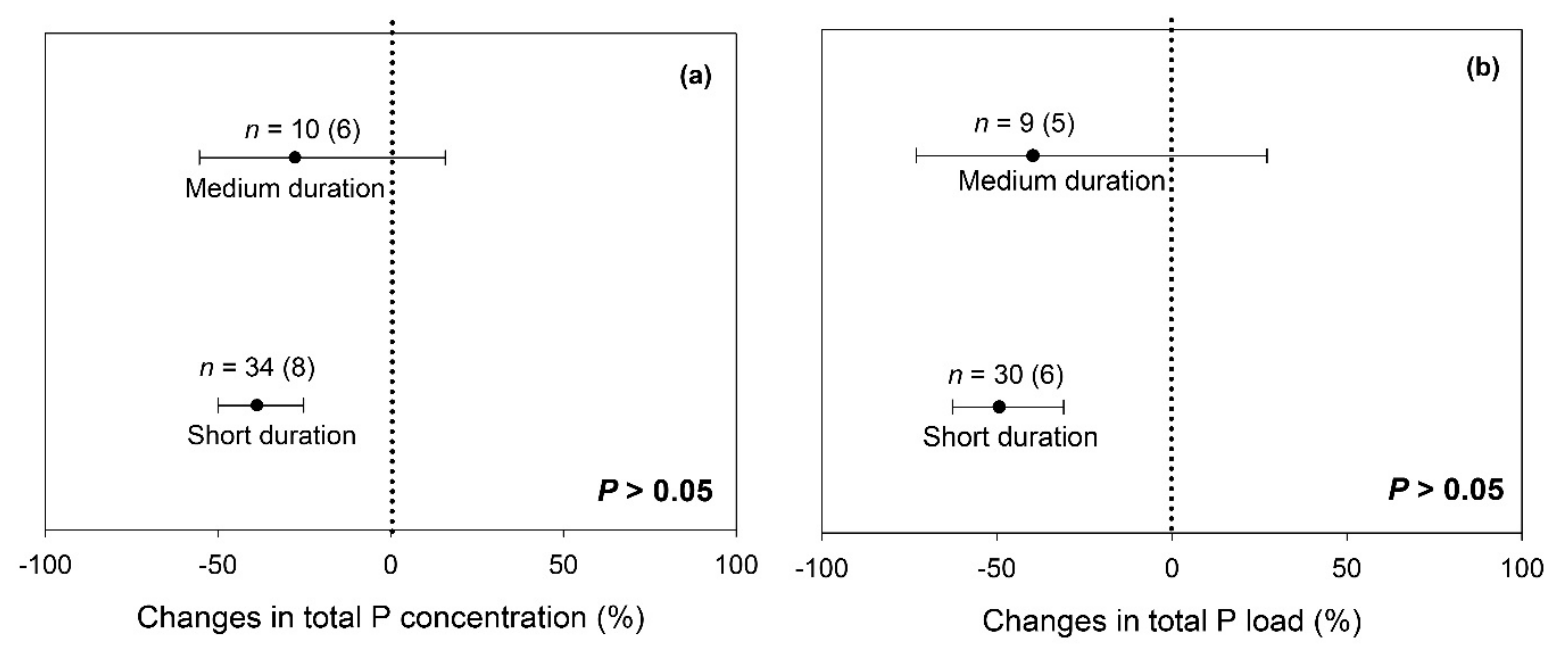

Suppl. Fig. S4 